\title{
The Intervention of Teacher's Written Feedback on Writing Proficiency
}

\author{
Mark Kolenberg ${ }^{1}$ Shirzad Mansouri ${ }^{2}$ \\ ${ }^{1} \mathrm{PhD}$. Student, Assumption University of Thailand \\ ${ }^{2}$ Full-time Lecturer, Assumption University of Thailand
}

\begin{abstract}
Writing teachers are interested to know if the feedbacks they give to their students are effective to improve their writing skills. There are three different approaches which have been introduced for such contribution. Form-focused feedback on one side can help students be aware of their mistakes so that they learn not to commit such mistakes in their writing and on the other side content focused feedback would help students write with their main concern which is content of what they write. Therefore, they are curious enough to know how which would be academically effective for the success of their teaching in the language classes. These teachers initiate instruction which might happen to focus on form or content, but in its communicative view, it has been suggested that focus on both will contribute to language development. As writing teachers and classroom researchers, it was a great critical issue to see which of these practical approaches would lead to better result and can bring more success for the students. Therefore, this study tries to find a teacher written feedback focus can improve student's writing proficiency in English. For this purpose, 120 students were selected and divided and selected into four groups (30 in each Group) based on stratified sampling done by office of registrar. The statistical method for the current study was based on Pre-test- Post-test experimental design which signifies the quantitative aspect of the study. Then the one-way ANOVA technique is used for data analysis. The data collected and corrected by the researchers from the students after 10 weeks of instruction indicated the existence of significant difference between pre-test and post-test results. It suggested possible effects of written feedback in grammar and content of the students' writing can contribute to their improvement.
\end{abstract}

Keywords: written feedback, intervention, writing proficiency, Thailand.

\section{Introduction}

The current movement in South East Asia towards a creation of united economic power (AEC) requires a unanimous language for effective communication among ASEAN members and their nations. Among such countries Thailand language education system couldn't prove to be effective to pave the way for Thai society to remove the big language barrier to achieve a pioneering leadership role in such a great economic event.

Assumption University of Thailand as the first international university in Thailand has been a major pioneer academic center in language education development and has followed the trend of language education with great concern on targeting country's development specifically in business and organizational leadership programs. The content taught in classes can successfully be mastered while students are striving tightly to acquire communicative competence provided by IELE team integrating great pains and joys of teaching English to new generation of young learners to use the English language for better and more effective communication. One area which is taken really seriously by IELE at the advanced level of English Language Learning Program is writing skill. It is very serious and important because it reflects the academic nature of students who are supposed to learn the knowledge in their area of interest through English.

\subsection{Research Question}

As an experienced teacher and a member of the IELE for more than five years, the researcher has been trying to find what kind teacher written feedback focus can improve students writing in English III.

Question : What kind of teacher's written feedback focus can improve students' writing in English III in IELE at Assumption University? 


\subsection{Research Hypothesis}

The following hypotheses are made on the basis of the presented research questions:

Hypothesis 1. Teacher's Form-focused written feedback can improve students' writing.

Hypothesis 2. Teacher's Content focused written feedback can improve students' writing.

Hypothesis 3. Teacher's Integrated focused written feedback can improve students' writing.

\subsection{Literature Review}

Writing teachers are interested to know if the feedbacks they give to their students are effective to improve their writing skills. There are three different approaches which have been introduced for such contribution. Form-focused feedback on one side can help students be aware of their mistakes so that they learn not to commit such mistakes in their writing and on the other side content focused feedback would help students write with their main concern which is content of what they write. Therefore, they are curious enough to know how which would be academically effective for the success of their teaching in the language classes. These teachers initiate instruction which might happen to focus on form or content, but in its communicative view, it has been suggested that focus on both will contribute to language development.

Form-focused feedback First of all, let me look through the research on the first type of teachers' feedback, form-focused feedback or grammar correction. As stated above, even though most of 12 teachers have been using this type of L2 writing instruction for such a long time, the effectiveness has remained one of most controversial issues among L2 scholars. Burt (1975) was one of those who first cast doubt on grammar correction, claiming that no current standards seem to exist on whether, when, which, or how learners errors should be corrected or who should correct them. Hendrickson also turned to the problem of teacher's error correction in grammar, approaching to this matter with more theoretical grounds. In a work published in is 1978, he reviewed available previous research and concluded that little was known about the efficacy of grammar correction. Posing pessimistic attitude toward the practice of teachefs correction on oral and written errors, he pointed out that the practice lacks theoretical grounds and is rather speculative. He added that even if form-focused feedback may be beneficial to students in some cases, it not necessarily an effective instructional strategy for every student or in all language classrooms as some empirical studies indicated. He claimed that, accordingly, continued research is required to substantiate the effectiveness of form-focused feedback in L2 writing classes.

The second type of feedback, which is known as content or meaning-based feedback. Unlike formfocused feedback, content-based feedback focuses more on content quality and organizational features in students' composition and teachers provide overall comments on where it doesn't make sense in terms of content or give some comments on logical fallacies in writing without pointing out specific grammatical errors. Since this type was put forth from the dubiousness of grammar correction, many researchers conducted their research to reveal the relative superiority comparing to form-focused feedback.

Teachers want to believe that the direct instruction such as correcting grammatical errors helps their students improve the accuracy of writing. Besides, they are concerned that if student's desire of teacher feedback is ignored, it might interfere with student's motivation and confidence in the writing class. For this reason, hypothesizing that integrating the two types of feedbacks can be more beneficial to learners, researchers wanted to verify the effectiveness of this form of feedback. First, Song (1998) aimed to research on which gives more positive effect on student's writing ability between meaning-related feedback and integrated feedback. This study exhibited that students with integrated feedback gained higher scores in holistic aspect as well as two analytical aspects such as content/organization and mechanics. However, there was no meaningful difference between content-based feedback and integrated feedback in aspects of vocabulary and style. Though students were not superior in writing style and word knowledge after receiving content-based feedback here, it was shown that integrated feedback is more effective and advantageous to improve L2 student's general writing skills in this study. 


\subsection{Research Methodology}

The purpose of this research is to investigate the teacher written feedback focus can improve students' writing proficiency. The researchers collect data from 120 students in English III in the academic semester, 2/2015 by using Stratified Sampling technique. Stratified Sampling technique select is used to divided students and selected into three groups based by office of registration, the students studying in IELE 30 students are in Experimental groups (EG1) and 30 in Experimental group (EG2) and 30 students in Experimental group (EG3) and 30 students in Control Group (CG4). The data was collected through pre-test and post-test design used and constructed by IELE testing section.

\subsection{Research Findings}

According to the data collection from the four groups of students studying in English 3 at IELE in 2/2015 here in Assumption University of Thailand, the Pre-test and Post-test results are as follows:

A. Descriptive Data for Pretest the results of the data collected from such administration were given to data analysis, and then the One Way ANOVA was applied to the current study.

TABLE 1.Descriptive statistics of four independent groups

\begin{tabular}{|l|r|r|r|r|r|}
\hline Treatment $\rightarrow$ & G1 & \multicolumn{1}{|c|}{ G2 } & G3 & G4 & Pooled Total \\
\hline observations N & \multicolumn{1}{|c|}{30} & \multicolumn{1}{|c|}{30} & \multicolumn{1}{|c|}{30} & 30 & \multicolumn{1}{|c|}{120} \\
\hline sum $\sum x i \sum \mathrm{xi}$ & 688.0000 & 694.0000 & 689.0000 & 692.0000 & $2,763.0000$ \\
\hline mean $x^{-} \mathrm{x}^{-}$ & 22.9333 & 23.1333 & 22.9667 & 23.0667 & 23.0250 \\
\hline sum of squares $\sum x 2 i \sum \mathrm{xi} 2$ & $15,936.0000$ & $16,206.0000$ & $16,011.0000$ & $16,110.0000$ & $64,263.0000$ \\
\hline sample variance $s 2 \mathrm{~s} 2$ & 5.4437 & 5.2230 & 6.4471 & 5.0989 & 5.4195 \\
\hline sample std. dev. & 2.3332 & 2.2854 & 2.5391 & 2.2581 & 2.3280 \\
\hline std. dev. of mean $S E x^{-} \mathrm{SEx}^{-}$ & 0.4260 & 0.4173 & 0.4636 & 0.4123 & 0.2125 \\
\hline
\end{tabular}

The summary of the data collected are given in table 1. Based on the data collected the summary of One Way ANOVA application technique is given in table 2.

TABLE 2.One-way ANOVA of four independent groups

\begin{tabular}{|c|c|c|c|c|c|}
\hline source & $\begin{array}{c}\text { sum of } \\
\text { squares SS }\end{array}$ & $\begin{array}{l}\text { degrees of } \\
\text { freedom }\end{array}$ & $\begin{array}{c}\text { mean square } \\
\text { MS }\end{array}$ & F statistic & p-value \\
\hline treatment & 0.7583 & 3 & 0.2528 & 0.0455 & 0.9870 \\
\hline error & 644.1667 & 116 & 5.5532 & & \\
\hline total & 644.9250 & 119 & & & \\
\hline
\end{tabular}

One Way ANOVA between the subjects in four groups was conducted to compare the effects of teachers' written feedback on the student writing proficiency. So base on the data displayed in table 4.2.F statistic is 0.0455 and the p-value 0.9870 which is bigger than $>.05$ which reflects that there is no significant difference among the groups at pretest stage. In other words it means statistically there is no difference between each pair of four groups participating in this study. Briefly it is shown that all the four groups at the beginning of the study are homogeneous in terms of writing proficiency.

B. Descriptive Data for Posttest After the treatment was done in each group and the final post-test was administrated to the four groups the descriptive data was collected and displayed in table 3 . 
TABLE 3.Descriptive statistics of four independent groups

\begin{tabular}{|c|c|c|c|c|c|}
\hline Treatment $\rightarrow$ & G1 & $\mathrm{G} 2$ & G3 & G4 & Pooled Total \\
\hline observations $\mathrm{N}$ & 25 & 25 & 25 & 25 & 100 \\
\hline $\operatorname{sum} \sum x i \sum \mathrm{xi}$ & 840.0000 & 814.0000 & $1,011.0000$ & 821.0000 & $3,486.0000$ \\
\hline mean $x^{-} \mathrm{x}^{-}$ & 33.6000 & 32.5600 & 40.4400 & 32.8400 & 34.8600 \\
\hline sum of squares $\sum x 2 i \sum x i 2$ & $28,876.0000$ & $27,156.0000$ & $40,929.0000$ & $27,605.0000$ & $124,566.0000$ \\
\hline sample variance $s 2$ s2 & 27.1667 & 27.1733 & 1.8400 & 26.8067 & 30.7479 \\
\hline sample std. dev. & 5.2122 & 5.2128 & 1.3565 & 5.1775 & 5.5451 \\
\hline std. dev. of mean $S E x^{-} S^{-}$ & 1.0424 & 1.0426 & 0.2713 & 1.0355 & 0.5545 \\
\hline
\end{tabular}

Following the application of One Way ANOVA technique table 4.shows the summary of the data collected. As it is shown in this table the ANOVA analysis have proven a statistically significant difference the means of four groups this means the significance level p-value equals.

The p-value corresponding to the F-statistic of one-way ANOVA is lower than 0.05, suggesting that the one or more treatments are significantly different. The Tukey test would likely identify which of the pairs of treatments are significantly different from each other since the numbers of participants were equal.

Tukey Test: The p-value corresponding to the F-statistic of one-way ANOVA is lower than 0.01 which strongly suggests that one or more pairs of treatments are significantly different. In this study there are four groups and four treatments, for which we shall apply Tukey's test to each of the six pairs to pinpoint which of them exhibits statistically significant difference.

TABLE 4.One-way ANOVA of four independent groups

\begin{tabular}{|l|r|r|r|r|r|r|}
\hline \multicolumn{1}{|c|}{ source } & $\begin{array}{c}\text { sum of } \\
\text { squares SS }\end{array}$ & $\begin{array}{c}\text { degrees of } \\
\text { freedom }\end{array}$ & $\begin{array}{c}\text { mean square } \\
\text { MS }\end{array}$ & F statistic & p-value \\
\hline treatment & $1,052.3600$ & 3 & 350.7867 & 16.9081 & $6.7746 \mathrm{e}-09$ \\
\hline error & $1,991.6800$ & 96 & 20.7467 & & \\
\hline
\end{tabular}

\section{Results and Conclusion}

The existence of significant difference between pre-test and post-test results suggest possible effects of written feedback in grammar and content of the students' writing. The results obtained from One-way ANOVA indicated that students improved in writing grammatical structure only when teacher gave them feedback on grammar mistakes and errors. However, these students in four groups significantly improved the content of their writing regardless the kind of feedback given in the classroom by the teacher. Students even improved the content and to some extend their grammar even when teacher provided no comments and or suggestions on the grammar and content of their original writing (Group 4 which received no treatment) though more significant improvement occurred when comments on content were provided. On the other hand, the students in Group 1 where they received feedback on their grammatical accuracy performed better than those who received no treatment while students who received only feedback comments on content (Group 2) showed more improvement in their writing with their content; yet they had more grammar mistakes. After being treated with grammatical and content feedback at the same time, students showed more improvement in both grammar and content of their writing. The strategy of identifying errors and mistakes have had greater effects on students' writing than general comments on content comments had in content because all students almost improved their grammatical accuracy when they received feedback on grammar.

\subsection{Further Study Directions}

The findings of the research suggested the following topic for further research as follows:

1. There is a need to know if the length of the students' writing or their fluency of writing is related to the type of written feedback given by the teacher. 
2. There is a need for further research if students' writing and rewriting or revisions are affected by the types of written feedback given by the teacher.

3. What is the students' verbal report on the type of written feedback given by the teacher?

The evidence-based findings from the current study leave certain related parts for more research and understanding.

\section{References}

[1] Ellis, R. (2001), Task-based language learning and teaching. Oxford: OUP.

[2] Ferris, D. R. (2004), The "Grammar Correction" Debate in L2 Writing: Where are we, and where do we go from here? (and what do we do in the meantime...?). Journal of Second Language Writing, pp. 49-62. http://dx.doi.org/10.1016/j.jslw.2004.04.005

[3] Gabrielatos, C. (2002), EFL writing: product and process. Retrieved September 29, 2013 from http://www.gabrielatos.com/Writing.pdf.

[4] Hyland, K. (2003), Second language writing. Cambridge: Cambridge University Press.

[5] Norris, J. and Ortega L. (2000), Effectiveness of L2 instruction: A research synthesis and quantitative meta-analysis. Language Learning, 50(3): pp. 417-528. http://dx.doi.org/10.1111/0023-8333.00136

[6] Park, E. (2006), Review Article on "The Effectiveness of Teacher's Written Feedback on L2 Writing". Retrieved from http://webcache.googleusercontent.com/search?q=cache:kC98w3t9Tw0J :sspace.snu.ac.kr/bitstream/10371/2051/1/workingpapers_v 5_61.pdf+\&cd=1\&hl= en\&ct=clnk\&gl=my\&client=firefox-a

[7] Schachter, J. (1991), Corrective feedback in historical perspective. Second Language Research, 7, pp. 89-102. http://dx.doi.org/10.1177/026765839100700202

[8] Spada, N. (1997), Form-focused instruction and second language acquisition: a review of classroom and laboratory research. Language Teaching, 30, pp. 73-87. http://dx.doi.org/10.1017/S0261444800012799

[9] Truscott, J. (1996), The case against grammar correction in L2 writing classes. Language Learning 46 (2): pp. $327-69$. http://dx.doi.org/10.1111/j.1467-1770.1996.tb01238.x

[10]Zamel, V. (1985), Responding to student writing. TESOL Quarterly, 19, pp. 79 -97. http://dx.doi.org/10.2307/3586773 